\title{
Comparison between the motor function of school-aged children with normal birth weight and children with low birth weight: a cross-sectional study
}

\author{
Amitava $\mathrm{Pal}^{1,2}$, Sourav Manna ${ }^{2,3}$, Prakash C. Dhara ${ }^{2}$ \\ ${ }^{1}$ Department of Physiology, Panskura Banamali College, Panskura, Purba Midnapore; ${ }^{2}$ Ergonomics and Sports Physiology \\ Division, Department of Human Physiology with Community Health, Vidyasagar University, Midnapore, India; \\ ${ }^{3}$ Department of Physiology, National Medical College, Birgunj, Parsa, Nepal.E-mail: amitavaergo@gmail.com \\ Received: 5th December 2017, Revised: 15th April 2018, Accepted: 30th April 2018
}

SUMMARY: Pal A, Manna S, Dhara PC. Comparison between the motor function of school-aged children with normal birth weight and children with low birth weight: a cross-sectional study. Turk J Pediatr 2019; 61: 374-385.

Low birth weight (LBW) children are prone to abnormal neurological signs in tone, coordination and reflexes, due to neonatal complications which lead to development of motor deficits and delays. The aim of the present study was a comparison between the motor function of school-age children with normal birth weight (NBW) and children with LBW. This study was conducted with 471 school-aged children from different districts of West Bengal, India. Different socio-demographic variables of the participants were studied by using a pre-structured schedule questionnaire. Gross motor function was studied by standing broad jump and vertical jump whereas fine motor function was studied by hand reaction time and speed of movement. Jumping skill was better among the boys than girls which implied that the gross motor skill of boys was better than girls. However, the hand reaction time and speed of movement among the girls was better than that of boys which implied that the fine motor skill of girls was better than boys. The postnatal growth of LBW children was significantly lower than that of NBW children. Both gross and fine motor performances of LBW children were significantly poorer than that of NBW children. This study found a strong association between birth weight and motor skills among school-age children even after controlling for the effects of age, gestational age, postnatal growth (height, weight and BMI) and socioeconomic status in a multivariable model. Thus, it appears that babies who are born with LBW have a tendency of neuro-developmental impairments during their childhood. Therefore, long-term monitoring programs and early detection and intervention is necessary in order to minimize future sequelae. The finding of this study indicates the importance of paying special attention to developmental follow up of high risk and LBW infants. It is proposed that more diagnostic evaluations be conducted on LBW infants for all aspects of development.

Key words: low birth weight, gross motor performance, fine motor performance.

Low birth weight (LBW) is one of the risk factors for child morbidity and mortality. ${ }^{1}$ Birth weight is an important indicator of a child's vulnerability to the risk of childhood illnesses and the chances of survival. Children whose birth weight is less than $2.5 \mathrm{~kg}$, are considered to have higher risk of early childhood death. ${ }^{2}$ The public health significance of LBW may be ascribed to numerous factors and its high incidence such as increased risk of perinatal and infant mortality, morbidity and disabilities, its association with mental retardation, etc. Worldwide, the magnitude of LBW problems varies widely from country to country. It is estimated that worldwide $15.5 \%$ of all live births per year are LBW. ${ }^{3}$ In India, about 30$35 \%$ babies are LBW. ${ }^{4}$ 
LBW babies have a less advantageous start to life that may have effects on their development as children and their adult lives. LBW babies are at an increased risk of developing learning, physical and sensory disabilities (hearing and visual impairments) that will present major challenges to them as developing children and adolescents in terms of their education and quality of life ${ }^{5}$. LBW babies have a greater chance of serious developmental problems, e.g. learning disabilities and mental retardation. ${ }^{5}$ Recent studies have shown that LBW infants are prone to abnormal neurological signs in tone, coordination and reflexes, due to neonatal complications which lead to the development of motor deficits and delays. ${ }^{6,7}$

"Motor" is defined as motion or relating to the movements of muscle. Motor and balance skills are part of the prerequisites for physical function and sports performance. ${ }^{8}$ Most motor skills are acquired by children during the period of preschool. ${ }^{8}$ Both motor and balance skills are also a fundamental milestone of the physical developmental in children. These skills are further polished for more complicated movements such as running, hopping and sports activities. Any impairment in motor and balance skills may increase the risk of falls and injuries even in healthy children. ${ }^{9}$ Motor skills can be categorized into two major groups which are gross motor skills and fine motor skills. ${ }^{10}$ Gross motor skills refer to large physical movements of the whole body. On the other hand, fine motor skills mean smaller movements, mainly movements in hands and fingers. Fine motor movements are more challenging for preschool children compared to gross motor movements. ${ }^{11}$

Premature infants occasionally have neurodevelopmental disabilities. ${ }^{12}$ Makrides et al. ${ }^{13}$ reported that infants born with LBW have poorer neuro-developmental outcomes compared to their counterparts with appropriate weight. Alshaikh et al. ${ }^{14}$ reported that sepsis in very low birth weight infants was associated with a worse neuro-developmental outcome and higher incidence of cerebral palsy. In a study by Wadhawan et al.Q it was reported that extremely LBW twins had a higher risk of neuro-developmental handicap. In another study, Wadhawan et al. ${ }^{16}$ stated that higher order extremely low birth weight births were associated with an increased risk of death or neuro-developmental impairment.

Hence, concise assessments and follow up of these children is of utmost importance in enabling early interventions and prevention of subsequent abnormal outcomes. Unfortunately, although several studies have been conducted to evaluate and examine the developmental outcomes of LBW infants and motor performance of LBW infants elsewhere, sufficient numbers of studies have not been conducted in this regard in India. The aim of the present study was to compare the motor function of school-age children with normal birth weight (NBW) and children with LBW.

\section{Material and Methods}

\section{Study design and study area}

This cross sectional study was conducted with 471 children with the age range of 5 to 10 years from different districts of West Bengal, India from September 2016 to February 2017.

The sample size was calculated by the standard formula $\left(\mathrm{n}=\mathrm{z}^{2} \mathrm{pq} / \mathrm{d}^{2}\right)^{17}$ using the following assumption: $22 \%$ of prevalence of LBW in West Bengal (NFHS-III 2005-2006), 95\% of confidence interval and $4 \%$ marginal error. The minimum estimated sample size was therefore 412 .

Out of the 471 children 210 (44.59\%) were girls. The mean age of children was $7.13 \pm 1.56$ years. The mean age of boys and girls were $7.07 \pm 1.52$ years and $7.21 \pm 1.6$ years, respectively and there was no significant difference in age of both sexes. The mean height, weight and BMI of the participants were $118.5 \pm 10.74 \mathrm{~cm}, 20.26 \pm 5.32 \mathrm{~kg}$ and $14.32 \pm 2.62 \mathrm{~kg} / \mathrm{m}^{2}$, respectively. The mean birth weight of the study participants was $2.59 \pm 0.51 \mathrm{~kg}$ (Table II).

Before the start of data collection, the purpose of the study, procedures of data collection and risks associated with the study were explained verbally in detail to the selected households to obtain their understanding and cooperation. Out of the households agreeing to take part in the study, informed consent was obtained from the participants 
during household visits. Participants suffering from any kind of psychiatric or neurological disturbances, any past or present history of major chronic diseases, participants who were taking psychotropic medicine for at least the last one month were excluded from the study. Home delivery and preterm birth were excluded from the present study. Before commencement of the study, ethical approval and prior permission was obtained from the Institutional Ethics Committee, Vidyasagar University (Vide No: VU/R/Ethical/3(ii)/2012, Dated-22.03.2012) and the study was carried out in accordance with the Helsinki declaration and with the ethical standards of the committee.

\section{Socio-demographic factors}

A pre-structured schedule questionnaire was used to assess socio-demographic variables (residence of the participants, religion, cast, parental education and occupation, per capita income, personal hygiene, type of house, number of individuals in the home, parity) of the study participants via house-to-house visits. Socioeconomic status of the participants was studied by modified Kuppuswami scale. ${ }^{18}$ The socioeconomic status of the participants was determined by the scores suggested in this scale. The score is obtained based on each participants' education, occupation and income which is added to get the final score, accordingly the participants were categorized. Five different categories from lower to upper have been suggested using the scale.

\section{Measurements}

Birth weight was the main independent variable or risk factor of interest because the focus of this study was to assess the association between birth weight and motor performance of children. The dependent variables of this study were gross and fine motor performance of children.

Birth weight and gestational age of the study participants were recorded from the antenatal card. The birth weight less than 2,500g was defined as LBW and birth weigh more or equal to $2,500 \mathrm{~g}$ was considered NBW. ${ }^{19}$ To conduct growth studies, assessment of age is most essential. The accurate age of the participants was recorded from their birth certificate. Height and weight of the participants were measured following the standard technique and appropriate landmarks. Motor performances of the participants were determined following standard procedures.

\section{Motor performances}

Fine motor performance: The fine motor performance of the study participants was determined by hand reaction time and speed of movement by using ruler catching methods. ${ }^{20}$

\section{Determination of hand reaction time:}

The reaction time may be defined as the interval of time between the presentation of stimulus and the initiation of response. ${ }^{20}$ This test is used to measure the reaction time of hand movement in response to a stimulus. The participants sat comfortably with his/her hand and forearm in resting condition on the table. The tips of the thumb and index finger were held in a ready to pinch position about 3 or 4 inches beyond the edges of the table. The upper edges of the thumb and index finger were in a horizontal position. The tester holds the stick timer near the top, letting it hang between the participant's thumbs and index finger. The participants were directed to look at the concentration zone and were told to react by catching the stick when it is released. The participants were not allowed to look at the tester's hand nor to move his/her hand up or down while attempting to catch the falling stick. The participants were allowed ten trials.

\section{Determination of speed of movement:}

The speed of movement may by defined as the rate at which a person adjusts the body or body parts between two things, i.e. the stimulus and what has to be done. To measure the speed of movement, time required for response of hand, foot etc. due to application of a stimulus is noted. The measurement of the speed of movement is based on the speed of movement on the law of constant acceleration of free falling bodies. ${ }^{20}$ The participants were seated at a table with his/her hands resting on the edges of the table. The palms were facing one another with the inside border of the little fingers along two lines which were marked on the edges of the cable 12 inches apart. The 
tester holds the timer near its top so that it hangs midway between the participant's palms. The base line was positioned so it is level with the upper borders of the participant's hands. After the preparatory command "ready" was given, the timer (ruler) was released and the participants clapped their hands together.

Gross motor performance: The gross motor performance of the study participants was determined by using a muscular power test. Muscular power test was performed by employing two tests; Standing Broad Jump Test ${ }^{21}$ and Vertical Jump Test (Sargent Jump Test). ${ }^{22}$ The Standing Broad Jump and Sargent Jump tests are considered very useful and valid methods for assessing power and jumping ability, especially due to its accessibility and feasibility. ${ }^{23}$ Several investigators used these tests as instruments for motor performance of children ${ }^{21,22,24}$ and strength measurement of players. ${ }^{23}$

\section{Standing broad jump:}

This test measures the power of legs in jumping a horizontal distance. A demonstration of the standing broad jump was given to the study participants. The participant was then asked to stand behind the starting line with the feet parallel to each other. The participant was instructed to jump as farthest as possible by bending knees and swinging arms to take off for the broad jump in the forward direction. The participants were given three trials. The distance between the starting line and the nearest point of landing provides the score of the test. The best (maximum distance) trial is used as the final score of the test.

\section{Vertical jump (Sargent jump):}

This test measures the power of legs in jumping vertically. The participant was asked to stand erect facing the wall. His/her dominant hand's fingertips were marked with chalk powder and the participant was asked to raise the marked fingertips to a maximum height on the wall without lifting the heels so as to mark his/her maximum reach point. The fingertips were rechalked. With the chalked hand side towards the wall, a vertical jump was to be performed by the participant to make another mark at the maximum height of the jump. The participant was not allowed to run or hop. The participants were given three trials and from there, the best single performance was considered.

\section{Quality control of the study}

To assure the quality of the data, properly designed data collection instrument and training of data collectors were ensured. The measurements were performed by a group of examiners (5 male and 5 female field examiners; BSc in Physiology). The principle investigators and the supervisor provided two days of training to the examiners on procedures, techniques and collecting the data including determining fine and gross motor performance, measurement of weight and height, etc. While collecting data, the instruments were regularly checked for their accuracy.

\section{Statistical analysis}

Frequency and percentage were used for categorical variables and mean and standard deviation were used for continuous variables to summarize data. To test the significant difference of different continuous variables, Students' t-test was performed. Pearson's correlation coefficient ( $r$ ) was computed to test the association between independent variable and dependent variables. To address the potential for confounding, multivariable linear regression analysis was undertaken. Birth weight, age, weight, height, BMI, gestational age and socioeconomic status of the participants were entered into the model as independent variables. Variables were retained in the model if they were significantly associated with indices of motor performance at $\mathrm{p}<0.05$. Statistical analyses were performed using the statistical software IBM SPSS version 20.

\section{Results}

The details of socio-demographic status of the study participants are presented in Table I. About $86 \%$ of the participants belonged to Hindu religion. Majority of participants were of rural residence $(75.16 \%)$. Most of the parents of the participants had low educational attainment. Most of the mothers of the participants were housewives $(90.02 \%)$. 
Table I. Socio-demographic Characteristics of Participants $(\mathrm{N}=471)$.

\begin{tabular}{|c|c|c|c|}
\hline Variables & Category & $\mathrm{N}$ & $\%$ \\
\hline \multirow[t]{2}{*}{ Residence } & Rural & 354 & 75.16 \\
\hline & Urban & 117 & 24.84 \\
\hline \multirow[t]{2}{*}{ Religion } & Hindu & 404 & 85.77 \\
\hline & Muslim & 67 & 14.23 \\
\hline \multirow[t]{2}{*}{ Cast } & General & 400 & 84.93 \\
\hline & $\mathrm{SC} / \mathrm{ST}$ & 71 & 15.07 \\
\hline \multirow[t]{3}{*}{ Educational status of father } & Illiterate/ able to sign & 32 & 6.79 \\
\hline & Primary & 218 & 46.28 \\
\hline & Secondary or above & 221 & 46.92 \\
\hline \multirow[t]{3}{*}{ Educational status of mother } & Illiterate/able to sign & 23 & 4.88 \\
\hline & Primary & 221 & 46.92 \\
\hline & Secondary or above & 227 & 48.20 \\
\hline \multirow[t]{2}{*}{ Father occupation } & Laborers/cultivator & 314 & 66.67 \\
\hline & Business/service & 157 & 33.33 \\
\hline \multirow[t]{3}{*}{ Mother occupation } & Cultivator & 38 & 8.07 \\
\hline & Housewife & 424 & 90.02 \\
\hline & Service & 9 & 1.91 \\
\hline \multirow[t]{3}{*}{ Housing condition } & Kanch & 158 & 33.55 \\
\hline & Semi pacca & 79 & 16.77 \\
\hline & Pacca & 234 & 49.68 \\
\hline \multirow[t]{2}{*}{ Availability of latrine } & No & 37 & 7.86 \\
\hline & Yes & 434 & 92.14 \\
\hline \multirow[t]{2}{*}{ Per capita income (Rs.) } & $\leq 2000$ & 341 & 72.4 \\
\hline & $>2000$ & 130 & 27.6 \\
\hline \multirow[t]{2}{*}{ Family size } & $\leq 4$ & 262 & 55.63 \\
\hline & $>4$ & 209 & 44.37 \\
\hline \multirow[t]{3}{*}{ Parity } & Primiparous & 314 & 66.67 \\
\hline & Pauciparous & 132 & 28.03 \\
\hline & Multiparous & 25 & 5.31 \\
\hline \multirow[t]{3}{*}{ Socioeconomic status } & Lower / upper lower & 291 & 61.78 \\
\hline & Lower middle & 126 & 26.75 \\
\hline & Upper middle / upper & 54 & 11.46 \\
\hline
\end{tabular}

Housing conditions were of a poor standard. About $8 \%$ of the households had no latrine at home and disposed excrement in the open surrounding the home. The mean family size of each household was 4.78 persons. The mean per capita income per month was about Rs. 1801/- (US \$ 26.88). More than $78 \%$ of participants had a monthly per capita income less than Rs 2,000/-. From the socioeconomic score it was noted that the majority of the participants belonged to upper lower or lower socioeconomic categories $(61.78 \%)$. A notable percentage of the participants were in the upper or upper middle categories $(11.46 \%)$.

Both gross and fine motor performances of 
Table II. Physical Dimension and Motor Performance of the 5 to 10 Years Children.

\begin{tabular}{|c|c|c|c|c|}
\hline \multicolumn{2}{|l|}{ Variables } & $\begin{array}{c}\text { Boy } \\
(\mathrm{N}=260)\end{array}$ & $\begin{array}{c}\text { Girl } \\
(\mathrm{N}=211)\end{array}$ & $\begin{array}{c}\text { All } \\
(\mathrm{N}=471)\end{array}$ \\
\hline \multicolumn{2}{|l|}{ Age (years) } & $7.07 \pm 1.52$ & $7.21 \pm 1.6$ & $7.13 \pm 1.56$ \\
\hline \multicolumn{2}{|l|}{ Weight $(\mathrm{kg})$} & $20 \pm 5.05$ & $20.59 \pm 5.62$ & $20.26 \pm 5.32$ \\
\hline \multicolumn{2}{|l|}{ Height $(\mathrm{cm})$} & $118.76 \pm 10.98$ & $118.18 \pm 10.43$ & $118.5 \pm 10.74$ \\
\hline \multicolumn{2}{|l|}{ BMI $(\mathrm{kg} / \mathrm{m} 2)$} & $14.1 \pm 2.57^{*}$ & $14.59 \pm 2.64^{*}$ & $14.32 \pm 2.62$ \\
\hline \multicolumn{2}{|l|}{ Birth weight $(\mathrm{kg})$} & $2.6 \pm 0.53$ & $2.58 \pm 0.48$ & $2.59 \pm 0.51$ \\
\hline \multicolumn{2}{|c|}{ Gestational age (weeks) } & $39.39 \pm 2.22$ & $39.61 \pm 2.08$ & $39.49 \pm 2.15$ \\
\hline \multicolumn{2}{|c|}{ Standing broad jump $(\mathrm{cm})$} & $114.9 \pm 30.7^{* *}$ & $107.08 \pm 28.08^{* *}$ & $111.4 \pm 29.78$ \\
\hline \multicolumn{2}{|l|}{ Vertical jump (cm) } & $29.6 \pm 12.53^{* * *}$ & $23.14 \pm 13.26^{* * *}$ & $26.71 \pm 13.24$ \\
\hline \multirow[t]{2}{*}{ Left hand } & Stick fall $(\mathrm{cm})$ & $34.9 \pm 10.95^{* * *}$ & $29.73 \pm 11.45^{* * *}$ & $32.58 \pm 11.45$ \\
\hline & RT (sec) & $0.263 \pm 0.043^{* * *}$ & $0.241 \pm 0.048^{* * *}$ & $0.254 \pm 0.047$ \\
\hline \multirow[t]{2}{*}{ Right and } & Stick fall $(\mathrm{cm})$ & $32.03 \pm 10.87^{* * *}$ & $27.47 \pm 11.35^{* * *}$ & $29.99 \pm 11.31$ \\
\hline & RT (sec) & $0.252 \pm 0.042^{* * *}$ & $0.232 \pm 0.048^{* * *}$ & $0.243 \pm 0.046$ \\
\hline \multirow[t]{2}{*}{ Speed of movement } & Stick fall $(\mathrm{cm})$ & $34.37 \pm 10.15^{* * *}$ & $30.68 \pm 10.98^{* * *}$ & $32.72 \pm 10.67$ \\
\hline & RT (sec) & $0.262 \pm 0.038^{* * *}$ & $0.246 \pm 0.043^{* * *}$ & $0.255 \pm 0.041$ \\
\hline
\end{tabular}

RT: reaction time

Results are presented as mean \pm standard deviation.

Comparison between genders: ${ }^{*} \mathrm{P}<0.5 ;{ }^{* *} \mathrm{P}<0.01$; ${ }^{* * *} \mathrm{P}<0.001$

the study participants were studied and from the results it was noted that the performances in standing broad jump and vertical jump of the participants was $111.4 \pm 29.78 \mathrm{~cm}$ and $26.71 \pm 13.24 \mathrm{~cm}$, respectively when both sexes were considered together. The left hand and right hand reaction times of the participants were $0.254 \pm 0.047 \mathrm{sec}$ and $0.243 \pm 0.046 \mathrm{sec}$, respectively. The speed of movement was $0.255 \pm 0.041 \mathrm{sec}$ (Table II). When the participants were stratified by sexes, the performances in standing broad jump and vertical jump of boys were significantly higher than that of girls which indicates that the gross motor performance of the boys was significantly better than the girls. The hand reaction time and speed of movement of boys were significantly higher than the girls which indicated that the fine motor performance of girls was significantly better than that of boys as lower reaction time represents better motor skill.

Out of the respondent, 189 children were classified as LBW and 282 were NBW. The mean age of the LBW and NBW children was $7.01 \pm 1.55$ years and $7.21 \pm 1.56$ years, respectively and no significant difference in age was obtained between LBW and NBW children (Table III). The mean height, weight and BMI of LBW children were significantly lower compared to the children born with birth weight $2.5 \mathrm{~kg}$ or more. The performances in standing broad jump and vertical jump were significantly lower among LBW children than that of NBW children in both sexes, which indicates the gross motor performances of LBW children was worse than that of NBW children. The fine motor performances were also significantly poorer in LBW children compared to NBW children as the hand reaction time and speed of movement of LBW children were significantly higher than the NBW children.

Correlation analysis demonstrated that the birth weight had a significant positive correlation with both gross motor performances [standing broad jump: $0.244(\mathrm{p}<0.001)$ and vertical jump: $0.271(p<0.001)]$ of the study participants which indicates that the gross motor performance increased with an increase in birth weight. A negative correlation was found between birth weight and fine motor performance [left hand reaction time: -0.337 $(p<0.001)$; right hand reaction time: -0.366 


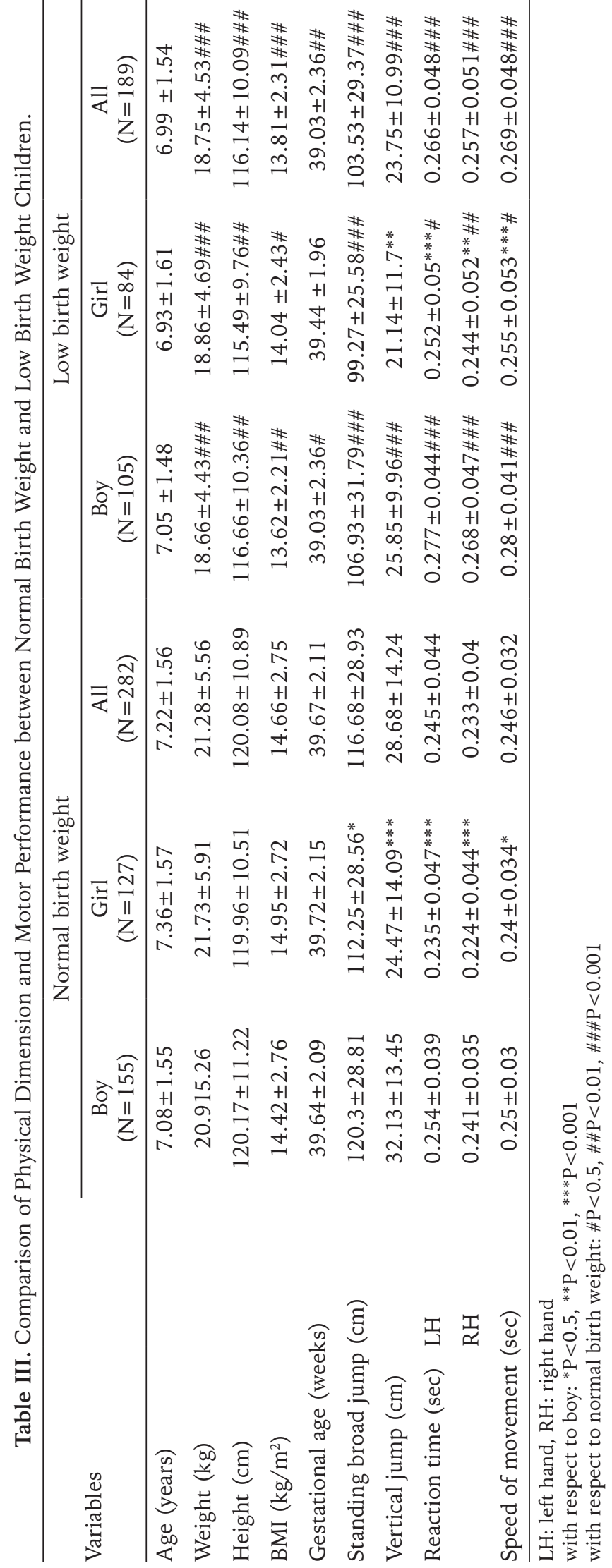

$(p<0.001)$ and speed of movement: $-0.369(p<0.001)]$ which confirms that children who were born with normal birth weight $(>2.5 \mathrm{~kg})$ had lower time reacting to a stimulus than that of low birth weight children.

Linear regression analyses of gross and fine motor performances with birth weight were performed and revealed that motor performances had significant associations with the birth weight of the children (Table IV and Fig. 1). Multiple regression analyses demonstrated that even after controlling for the effect of age, gestational age, postnatal growth (height, weight and BMI) and socioeconomic status, birth weight had the strongest significant impact on motor performances of the children.

\section{Discussion}

With advances in medical and neonatal intensive care, the survival of high risk neonates has been improved considerably. However, children born with low birth weight are at high risk for poor developmental outcomes due to a variety of risk factors that have been found in these high risk neonates. Several studies have reported significant motor impairments in LBW children. ${ }^{7,25,26}$ Motor dysfunction may affect the child's exploration of the world, involvement in social activities and advancement of handwriting skills. ${ }^{25,26}$ Weaken motor development of these low birth weight children is a risk factor for later poor cognitive performance, learning disabilities, and behaviour problems. ${ }^{27,28}$ This highlights the importance of studying the motor consequences of LBW children.

In the present study, boys' jumping skills were better than girls which implies the gross motor skill of boys was better than girls. The finding of our study was similar to the study done by Vameghi et al. ${ }^{29}$ in which they reported that the jumping and ladder climbing skills were better among boys 
Table IV. Regression Analysis of Motor Performance as Dependent and Birth Weight as Independent Variables.

\begin{tabular}{|c|c|c|c|c|c|c|c|c|c|c|}
\hline & \multicolumn{4}{|c|}{ Unadjusted } & \multicolumn{4}{|c|}{ Adjusted\# } \\
\hline & & & B & $\mathrm{SeB}$ & $\beta$ & $\mathrm{t}$ & B & $\mathrm{SeB}$ & $\beta$ & $\mathrm{t}$ \\
\hline \multirow[t]{5}{*}{ Boy } & \multicolumn{2}{|c|}{ Standing broad jump } & 14.871 & 3.472 & 0.258 & $4.283^{* *}$ & 15.025 & 3.541 & 0.26 & $4.244^{* *}$ \\
\hline & \multicolumn{2}{|c|}{ Vertical jump } & 7.931 & 1.381 & 0.337 & $5.743^{* *}$ & 8.28 & 1.431 & 0.351 & $5.786^{* *}$ \\
\hline & \multirow{2}{*}{$\begin{array}{l}\text { Reaction } \\
\text { time }\end{array}$} & LH & -0.03 & 0.005 & -0.374 & $6.484^{* *}$ & -0.028 & 0.005 & -0.349 & $5.619^{* *}$ \\
\hline & & RH & -0.032 & 0.005 & -0.397 & $6.94^{* *}$ & -0.03 & 0.005 & -0.382 & $6.164^{* *}$ \\
\hline & \multicolumn{2}{|c|}{ Speed of movement } & -0.033 & 0.004 & -0.47 & $8.551^{* *}$ & -0.03 & 0.004 & -0.423 & $7.235^{* *}$ \\
\hline \multirow[t]{5}{*}{ Girl } & \multicolumn{2}{|c|}{ Standing broad jump } & 13.51 & 3.903 & 0.233 & $3.461^{* *}$ & 13.846 & 3.972 & 0.239 & $3.486^{* *}$ \\
\hline & \multicolumn{2}{|c|}{ Vertical jump } & 5.355 & 1.859 & 0.195 & $2.881^{*}$ & 3.382 & 1.892 & 0.123 & 1.788 \\
\hline & \multirow{2}{*}{$\begin{array}{l}\text { Reaction } \\
\text { time }\end{array}$} & LH & -0.029 & 0.007 & -0.291 & $4.391^{* *}$ & -0.028 & 0.007 & -0.279 & $4.017^{* *}$ \\
\hline & & $\mathrm{RH}$ & -0.033 & 0.007 & -0.327 & $5.011^{* *}$ & -0.032 & 0.007 & -0.32 & $4.664^{* *}$ \\
\hline & \multicolumn{2}{|c|}{ Speed of movement } & -0.025 & 0.006 & -0.276 & $4.148^{* *}$ & -0.023 & 0.006 & -0.26 & $3.687^{* *}$ \\
\hline \multirow[t]{5}{*}{ All } & \multicolumn{2}{|c|}{ Standing broad jump } & 14.492 & 2.609 & 0.248 & $5.555^{* *}$ & 13.842 & 2.635 & 0.237 & $5.253^{* *}$ \\
\hline & \multicolumn{2}{|c|}{ Vertical jump } & 7.037 & 1.153 & 0.271 & $6.105^{* *}$ & 6.347 & 1.182 & 0.245 & $5.372^{* *}$ \\
\hline & \multirow{2}{*}{$\begin{array}{l}\text { Reaction } \\
\text { time }\end{array}$} & LH & -0.029 & 0.004 & -0.32 & $7.303^{* *}$ & -0.027 & 0.004 & -0.298 & $6.53^{* *}$ \\
\hline & & $\mathrm{RH}$ & -0.032 & 0.004 & -0.349 & $8.063^{* *}$ & -0.03 & 0.004 & -0.332 & $7.292^{* *}$ \\
\hline & \multicolumn{2}{|c|}{ Speed of movement } & -0.03 & 0.003 & -0.368 & $8.566^{* *}$ & -0.028 & 0.004 & -0.346 & $7.676^{* *}$ \\
\hline
\end{tabular}

LH: left hand, RH: right hand

${ }^{*} \mathrm{P}<0.01,{ }^{* *} \mathrm{P}<0.001$

\#after adjustment for age, postnatal growth (weight, height, BMI), gestational age, socioeconomic status

than that of girls. However, the hand reaction time and speed of movement among girls was better than that of boys which implies the fine motor skills of girls was better than boys. This finding is in line with a study done by Largo et al. $^{30}$. Neural pathways were an important factor for motor systems and underline that patterned movements may mature differently in girls than boys. Chen et al. ${ }^{31}$ reported that the left hemisphere was more involved in the timing of complex sequences than the right hemisphere. Similar findings were reported by Grafton et al. ${ }^{32}$. They stated that time related task involvement of the left hemisphere was greater than the right hemisphere. Grafton et $\mathrm{al}^{32}$ and Haaland et al. ${ }^{33}$ reported that development of the left hemisphere in girls was faster than boys. This might be the reason for gender differentiation of motor performances of the children.

The postnatal growth of LBW children was significantly lower than that of normal birth weight children. Both gross and fine motor performances of low birth weight children were significantly poorer than that of normal birth weight children. Arifeen et al. ${ }^{34}$ studied infant growth patterns and their relations to birth weight in low socio-economic conditions in Dhaka, Bangladesh and found that birth weight was the most important determinant of subsequent growth status during infancy. A number of studies have reported that poor birth weight leads to increased risk of disease morbidity and mortality due to malnutrition. ${ }^{35,36}$ LBW survivors demonstrate significant growth retardation, as reflected by lower body weights and heights, in comparison to their normal weight peers. ${ }^{37}$ Although there is some tendency for growth catch up, the deficits persist even up till 14 years of age. ${ }^{37}$ Greater morbidity among children with LBW results in poor physical growth and development that is perceived as malnutrition. Ramakrishnan $^{38}$ found that children with LBW experienced growth failure during early childhood and into the adolescence period. Rahman et $\mathrm{al}^{39}$ reported that once a baby was born as LBW, the risk of becoming malnourished during the first five years of 

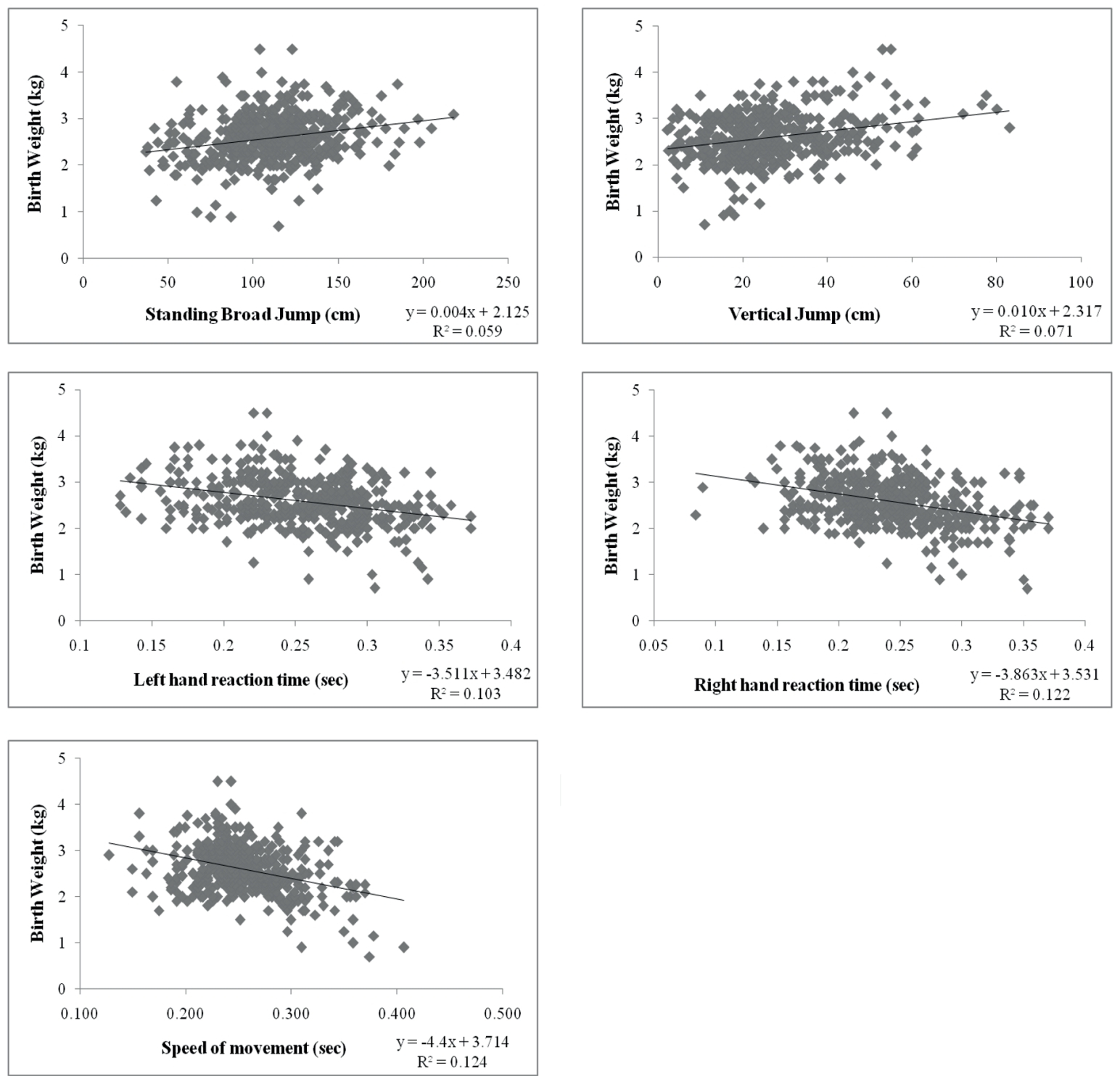

Fig. 1. Scatter diagram of birth weight and motor performances of children.

life was higher compared to a baby of normal birth weight even if the mother was educated, household socio-economic conditions were good, and the preceding birth interval was long. Infants born with LBW remain growth retarded through early childhood and the deficit in weight is primarily attributable to deficits in lean body mass. ${ }^{40,41}$ Differences in motor performance among low birth weight children and normal birth weight children may be affected by these differences in muscularity associated with birth status. The acquisition of appropriate motor skills might be delayed among children born with LBW who have reduced musculature.
This study found a strong association between birth weight and motor skills among schoolage children even after controlling for other factors in a multivariable model. Therefore, birth weight may be the best account for the variability of motor performances of children. It can therefore be inferred that NBW children were faster in reacting to stimuli compared to LBW children. Thus, it appears that babies who are born with LBW have a tendency of neurodevelopmental impairments during their childhood. The observed association between birth weight and motor function is consistent with the findings of other studies. ${ }^{42-44}$ de Kieviet et al. $^{42}$ reported that being born 
LBW was associated with significant motor impairment persisting throughout childhood. Grantham et al. ${ }^{43}$ showed that LBW infants had significantly lower scores in mental and psychomotor development index. In a study by Datar and Jacknowitz ${ }^{44}$, mental and motor development of LBW babies during the first two years of life was compared with those of normal birth weight ones and reported that LBW had an adverse effect on mental and motor development in the first two years of life. Children born with low birth weight may suffer from many neurodevelopmental disabilities. ${ }^{13-15}$ The incidence of cerebral palsy among LBW infant was higher compared to infants born with a weight of $2.5 \mathrm{~kg}$ or more. ${ }^{14}$ The neuro-developmental outcome of infants born with low birth weight was poorer than that of NBW infants. ${ }^{13}$ Sepsis in very LBW infants was prevalent and associated with a worse neurodevelopmental outcome. ${ }^{14}$

The results of the present study indicate that LBW children are at risk for neurodevelopmental impairments. The motor performance of LBW children was significantly lower than that of children who were born with normal birth weight. Birth weight had the strongest significant impact on motor performances of school-age children even after controlling for other factors. Therefore, it can be concluded that LBW infants are more susceptible to poor motor performance. To prevent such impairments, numerous interventions for LBW children have been reported. Filteau et $a l .{ }^{45}$ reported that vitamin D supplements could potentially lead to benefits for motor development through effects on bone and muscle, and their interaction, could affect motor performance. Physical exercise can also increase bone density as well as improve motor performance. ${ }^{45}$ Although LBW children had a greater tendency to develop malnutrition, LBW children could grow very fast soon after birth and catch-up in growth, reaching a weight within the normal range for their age within 6-9 months if they get enough breastmilk. ${ }^{46}$ Therefore, it is necessary to implement longterm monitoring programs and early detection and intervention in order to minimize future sequelae. The finding of this study indicates the importance of paying special attention to developmental follow up of high risk and LBW infants. It is proposed that more diagnostic evaluations be conducted on LBW infants for all aspects of development.

In the present study birth weight, age, gestational age, postnatal growth and socioeconomic status affecting the child's motor performance were studied, however some important confounding variables such as physical activity of the child, parasitic infection, child's history of illness, daily intake, etc. were not studied. There are limitations associated with using cross-sectional data, as cross-sectional nature of the study design cannot establish the causal relationships of the predictors and the outcome variables.

\section{Acknowledgments}

All the authors wish to express their gratitude to the participants who volunteered for this study.

\section{REFERENCES}

1. Lawn JE, Cousens S, Zupan J; Lancet Neonatal Survival Steering Team. 4 million neonatal deaths: When? Where? Why? Lancet 2005; 365: 891-990.

2. Central Statistical Agency (Ethiopia) and ORC Macro. Ethiopia Demographic and Health Survey 2005. Addis Ababa, Ethiopia and Calverton, Maryland, USA: Central Statistical Agency and Macro 2006. Available at: https:// unicef.org/ethiopia/DHS_2005_Ethiopia. pdf

3. Gebremedhin M, Ambaw F, Admassu E, Berhane H Maternal associated factors of low birth weight: A hospital based cross-sectional mixed study in Tigray, Northern Ethiopia. BMC Pregnancy Childbirth 2015; 15: 222.

4. Dalal A, Chauhan S, Bala DV. Epidemiological determinants of low birth weight in Ahmedabad city: A facility based case-control study. Int J Med Sci Public Health 2014; 3: 430-432.

5. Balanda KP, McAvoy HA. Unequal at birth: Inequalities in the occurrence of low birthweight babies in Ireland. The Institute of Public Health in Ireland, 2006.

6. Samsom JF, de Groot L, Bezemer PD, Lafeber HN, Fetter WP. Muscle power development during the first year of life predicts neuromotor behaviour at 7 years in preterm born high-risk infants. Early Hum Dev 2002; 68: 103-118.

7. Nazi S, Aliabadi F. Comparison of motor development of low birth weight (LBW) infants with and without using mechanical ventilation and normal birth weight infants. Med J Islam Repub Iran 2015; 29: 301. 
8. Venetsanou F, Kamba A. The effects of age and gender on balance skills in preschool children. Phys Educ Sport 2011; 9: 81-90.

9. Willems TM, Witvrouw E, Delbaere K, Philippaerts $\mathrm{R}$, De Bourdeaudhuij I, De Clercq D. Intrinsic risk factors for inversion ankle sprains in females-a prospective study. Scand J Med Sci Sports 2005; 15: 336-345

10. Oswalt A. Early childhood physical development: Gross and fine motor development 2016. Available at: https://gulfbend.org/poc/view doc. php? type $=\operatorname{doc} \& i d=12755 \& \mathrm{cn}=5$

11. Benelli C, Yongue B. Supporting young children's motor skill development. Child Educ 1995; 71: $217-$ 220.

12. Lenke MC. Motor outcomes in premature infants. Newborn Inf Nurs Rev 2003; 3: 104-109.

13. Makrides M, Anderson A, Gibson RA, Collins CT. Improving the neurodevelopmental outcomes of low birth weight infants. In: Bhatia J, Bhutta ZA, Kalhan SC (eds): Maternal and Child Nutrition: The First 1000 Days. Nestlé Nutr Inst Workshop Ser. Nestec Ltd, Vevey/S. Karger AG, Basel 2013; 74: 211-221.

14. Alshaikh B, Yusuf K, Sauve R. Neurodevelopmental outcomes of very low birth weight infants with neonatal sepsis: Systematic review and meta-analysis. J Perinatol 2013; 33: 558-564.

15. Wadhawan R, Oh W, Perritt RL, et al. Twin gestation and neurodevelopmental outcome in extremely low birth weight infants. Pediatrics 2009; 123: e220-e227.

16. Wadhawan R, Oh W, Vohr BR, et al; Eunice Kennedy Shriver National Institute of Child Health \& Human Development Neonatal Research Network. Neurodevelopmental outcomes of triplets or higherorder extremely low birth weight infants. Pediatrics 2011; 127: e654-e660.

17. Pal A, De S, Sengupta P, Maity P, Goswami S, Dhara PC. Re-evaluation of WHO-defined BMI cut-off value for defining overweight and obesity in the Bengalee (Indian) population. Med J Nutrition Metab 2013; 6: 31-37.

18. Kumar BPR, Dudala SR, Rao AR. Kuppuswamy's socio-economic status scale - A revision of economic parameter for 2012. Int J Res Dev Health 2013; 1: 2-4.

19. Kramer MS. Determinants of low birth weight: Methodological assessment and meta-analysis. Bull World Health Organ 1987, 65: 663-737.

20. Johnson BL,Nelson JK. Practical Measurements for Evaluation in Physical Education. New Delhi, India: Surjeet Publications, 1988.

21. Merriman WJ, Barnett BE, Kofka JB. The standing long jump performances of preschool children with speech impairments and children with normal speech. Adapt Phys Act Q 1993; 10: 157-163.
22. Ayán-Pérez C, Cancela-Carral JM, Lago-Ballesteros J, Martínez-Lemos I. Reliability of Sargent Jump Test in 4- to 5-year-old children. Percept Mot Skill 2017; 124: 39-57.

23. da Costa Mendes de Salles PG, Vasconcellos FVA, da Costa Mendes de Salles GF, Fonseca RT, Dantas EHM. Validity and reproducibility of the Sargent Jump Test in the assessment of explosive strength in soccer players. J Hum Kinet 2012; 33: 115-121.

24. Duncan MJ, Lawson C, Walker LJ, Stodden D, Eyre ELJ. The utility of the supine-to-stand test as a measure of functional motor competence in children aged 5-9 years. Sports (Basel) 2017; 5: 67.

25. Powls A, Botting N, Cooke RW, Marlow N. Motor impairment in children 12 to 13 years old with a birthweight of less than 1250 g. Arch Dis Child Fetal Neonatal Ed 1995; 73: F62-F66.

26. de Kieviet JF, Piek JP, Aarnoudse-Moens CS, Oosterlaan J. Motor development in very preterm and very low-birth-weight children from birth to adolescence. A meta-analysis. JAMA 2009; 302: 2235-2242.

27. Bhutta AT, Cleves MA, Casey PH, Cradock MM, Anand KJ. Cognitive and behavioral outcomes of school-aged children who were born preterm: A meta-analysis. JAMA 2002; 288: 728-737.

28. Aarnoudse-Moens CS, Weisglas-Kuperus N, van Goudoever JB, Oosterlaan J. Meta-analysis of neurobehavioral outcomes in very preterm and/or very low birth weight children. Pediatrics 2009; 124 : 717-728.

29. Vameghi R, Shams A, Dehkordi PS. The effect of age, sex and obesity on fundamental motor skills among 4 to 6 years-old children. Pak J Med Sci 2013; 29: 586589

30. Largo R, Caflisch J, Hug F, Muggli K, Molnar AA Molinari L. Neuromotor development from 5 to 18 years. Part 2: Associated movements. Dev Med Child Neurol 2001; 43: 444-453.

31. Chen R, Gerloff C, Hallett M, Cohen L. Involvement of the ipsilateral motor cortex in finger movements of different complexities. Ann Neurol 1997; 41: 247 254.

32. Grafton S, Hazeltine E, Ivry RB. Motor sequence learning with the nondominant left hand: A PET functional imaging study. Exp Brain Res 2002; 146: 369-378.

33. Haaland KY, Elsinger CL, Mayer AR, Durgerian S, Rao S. Motor sequence complexity and performing hand produce differential patterns of hemispheric lateralization. J Cogn Neurosci 2004; 16: 621-636.

34. Arifeen SE, Black RE, Caulfield LE, et al. Infant growth patterns in the slums of Dhaka in relation to birth weight, intrauterine growth retardation, and prematurity. Am J Clin Nutr 2000; 72: 1010-1017. 
35. Haque SMR, Tisha S, Huq N. Poor birth size a badge of low birth weight accompanying less antenatal care in Bangladesh with substantial divisional variation: Evidence from BDHS-2011. Publ Health Res 2015; 5: 184-191.

36. Motta MEFA, da Silva GAP, Araújo OC, Lira PI, Lima MC. Does birth weight affect nutritional status at the end of first year of life? J Pediatr 2005; 81: 377-382.

37. Bhargava SK, Ramji S, Srivastava U, et al. Growth and sexual maturation of low birth weight children: A 14 year follow up. Indian Pediatr 1995; 32: 963-970.

38. Ramakrishnan U. Nutrition and low birth weight: From research to practice. Am J Clin Nutr 2004; 79: 17-21.

39. Rahman MS, Howlader T, Masud MS, Rahman ML. Association of low-birth weight with malnutrition in children under five years in Bangladesh: Do mother's education, socio-economic status, and birth interval matter? PLoS One 2016; 11: e0157814.

40. Hediger ML, Overpeck MD, Maurer KR, Kuczmarski RJ, McGlynn A, Davis WW. Growth of infants and young children born small- or large-for-gestationalage: Findings from the third National Health and Nutrition Examination Survey. Arch Pediatr Adolesc Med 1998; 152: 1225-1231.
41. Hediger ML, Overpeck MD, Ruan WJ, Troendle JF Birthweight and gestational age effects on motor and social development. Paediatr Perinat Epidemiol 2002; 16: 33-46.

42. de Kieviet JF, Piek JP, Aarnoudse-Moens CS, Oosterlaan J. Motor development in very preterm and very low-birth-weight children from birth to adolescence: A meta-analysis. JAMA 2009; 302: 2235-2242.

43. Grantham-Mc Gregor SM, Lira PIC, Ashworth A, Morris SS, Assunçao AMS. The development of low birth weight term infants and the effects of the environment in northeast Brazil. J Pediatr 1998; 132: 661-666.

44. Datar A, Jacknowitz A. Birth weight effects on children's mental, motor, and physical development: Evidence from twins data. Matern Child Health J 2009; 13: 780-794.

45. Filteau S, Rehman AM, Yousafzai A, et al. Associations of vitamin D status, bone health and anthropometry, with gross motor development and performance of school-aged Indian children who were born at term with low birth weight. BMJ Open 2016; 6: e009268.

46. Subasinghe SMLP, Wijesinghe DGNG. The effect of nutritional status on cognitive and motor development of pre-school children. Trop Agr Res 2006; 18: 87-95. 